\title{
APROBAR AL PRESIDENTE. UNA COMPARACIÓN ENTRE FELIPE CALDERÓN Y ENRIQUE PEÑA NIETO
}

\author{
APPROVING THE PRESIDENT. \\ A COMPARISON BETWEEN FELIPE CALDERÓN \\ AND ENRIQUE PEÑA NIETO \\ APPROUVER LE PRÉSIDENT. \\ FELIPE CALDERÓN COMPARÉ À ENRIQUE PEÑA NIETO \\ Ma. Fernanda Somuano \\ El Colegio de México \\ f.somuano@colmex.mx
}

Resumen: La aprobación pública del Presidente juega un papel fundamental en el poder y la legitimidad con los que cuenta y en el éxito potencial que pueden tener sus decisiones de política. Este trabajo analiza y compara los determinantes de la aprobación presidencial de dos presidentes mexicanos, a saber: Felipe Calderón y Enrique Peña Nieto. Los datos que utilizo son dos oleadas de la Encuesta de las Américas 2008 y 2014. Entre los hallazgos más importantes, encuentro que, por un lado, los temas que prevalecieron en la prensa (los cuales, de algún modo, son los mismos que predominaron en los discursos presidenciales) coinciden de manera significativa con aquellos que los ciudadanos perciben como el asunto más importante para ellos. Por otro, aun con presidentes distintos, inmersos en coyunturas distintas, el tema económico es el que más pesa en la evaluación de su desempeño. Con todo, el tema de la inseguridad y el de la corrupción aparecen y permanecen durante los dos sexenios como temas que se mantienen con un efecto significativo en la ecuación de la aprobación presidencial.

Palabras clave: Aprobación presidencial, Presidente, popularidad, Calderón, Peña Nieto.

Abstract: Public approval for the President plays a fundamental role in the power and legitimacy he enjoys and in the potential success of his policy decisions. This paper analyzes and compares the factors determining the presiden- 
tial approval of two Mexican presidents: Felipe Calderón and Enrique Peña Nieto. The data I use are taken from two series of the Survey of the Americas 2008 and 2014. Among the most important findings I find that, on the one hand, the issues that prevailed in the press (which to some extent are the same as those that predominated in presidential speeches) coincide significantly with those that citizens perceive as the most important issues for them. On the other, even with different presidents, in different situations, economic issues are the ones that weigh most heavily in the evaluation of their performance. However, the issues of insecurity and corruption appear and remain during the two six-year terms in office as issues that continue to have a significant effect on the presidential approval rating.

Keywords: Presidential approval ratings, president, popularity, Calderón, Peña Nieto.

Traducción de Gonzalo Celorio Morayta

Résumé: L'approbation publique dont bénéficie le Président est indispensable à sa légitimité, à son pouvoir et à l'efficacité potentielle de ses décisions politiques. L'article analyse et compare les déterminants de cette approbation envers deux présidents mexicains: Felipe Calderón et Enrique Peña Nieto. Les données utilisées proviennent de l'Enquête des Amériques en 2008 et 2014. L'analyse met en évidence que les thèmes dominants dans la presse, qui en général le sont aussi dans le discours présidentiel, sont également perçus par les citoyens comme les plus importants pour eux-mêmes. D'autre part, malgré les différences entre ces deux présidents, contraints par des circonstances diverses, la question de l'économie est celle qui pèse le plus au moment d'évaluer leur rendement, bien que les problèmes liés à l'insécurité et à la corruption figurent aussi, le long des deux périodes présidentielles, parmi ceux qui importent le plus pour l'évaluation.

Mots clefs: Approbation vis-à-vis du Président, Président, popularité, Calderón, Peña Nieto.

Traducción de Bernardo MabiRe

Fecha de recepción: enero de 2017 Fecha de aceptación: mayo de 2018 
L

A APRobación PÚblica* del Presidente desempeña un papel fundamental en el poder y la legitimidad con los que cuenta y en el éxito potencial que pueden tener sus decisiones de política. Un presidente con altos niveles de aprobación cuenta con un mayor margen de maniobra para negociar con los partidos de oposición en la legislatura y con los gobiernos subnacionales para obtener su apoyo en la implementación de sus políticas. Con todo, no es evidente ni qué determina que el ciudadano califique bien o mal al Presidente, por una parte, ni qué temas o asuntos tome en cuenta para evaluar al que está en turno, por otra. ¿Será acaso el económico, como no pocos han apuntado ya, el tema que descuelle por sobre los demás en su evaluación?

Este trabajo analiza y compara los determinantes de la aprobación presidencial en los casos de Felipe Calderón y Enrique Peña Nieto. Los datos que utilizo son dos oleadas de la Encuesta de las Américas (LAPOP) 2008 y 2014. Haber elegido México como caso de estudio es relevante, porque, primero, a causa de la inmensa escalada en varios indicadores de incidencia delictiva (incluida la tasa de homicidio) durante la administración de Calderón, puede analizarse si el de la seguridad se posicionó como tema relevante en el cálculo de los ciudadanos al evaluar la gestión de éste (hay que señalar que hasta entonces los temas económicos eran los más importantes en ese cálculo) y, segundo, si la decisión del presidente Peña Nieto de centrar su discurso alrededor de las reformas estructurales y colocar ese tema por encima de los de seguridad y economía logró que las reformas se colocaran como un asunto determinante de la evaluación de los ciudadanos sobre su gestión. Analizar dos presidentes en un mismo país también es relevante, porque me permite mantener constantes las variables institucionales. De tal suerte que si en dos

* Agradezco a Valeria Molina y a Francisco Lobato por el meticuloso trabajo de revisión de prensa que hicieron y que es parte fundamental de este artículo. Igualmente, agradezco la asesoría de Melina Altamirano en la elaboración de los modelos y a René Uriel Macías en la de cuadros y gráficas. 
circunstancias completamente distintas con dos presidentes diferentes son los mismos temas los que aparecen como determinantes de su aprobación, puedo intuir que esos asuntos son importantes no tanto coyuntural, cuanto formalmente.

Este trabajo intenta contribuir al entendimiento de los determinantes de la aprobación presidencial en México. Sin embargo, no descarta que algunas de las conclusiones puedan extrapolarse a otros países. A la inversa de otros estudios, éste no sólo se centra en el tema económico, que es el que más se ha estudiado, sino que incorpora otros temas como los de la seguridad y la corrupción, que en este país han dejado de ser coyunturales y han pasado a ser parte de la cotidianeidad de los mexicanos. El artículo es comparativo, por lo que permite evaluar si son los mismos temas los que consideran los ciudadanos al evaluar a dos presidentes distintos. Pretende, en fin, tender un puente entre las bibliografías especializadas de media priming y la tradicional a propósito de la evaluación presidencial que se centra en las características y percepciones individuales, sin indagar la posible influencia de otros agentes en tales percepciones.

El trabajo muestra hallazgos interesantes. Hallo que los temas que prevalecieron en la prensa (que, de algún modo, son los mismos que predominaron en los discursos presidenciales) coinciden de manera significativa con aquellos que los ciudadanos perciben como el asunto más importante para ellos. Sí hay una coincidencia entre el problema que la gente percibe como el más importante y el tema que tiene mayor influencia en la evaluación presidencial, el económico, seguido del de inseguridad y el de la corrupción en tercer lugar. Aun con presidentes distintos, puestos en coyunturas distintas, el tema económico es el que más pesa en la evaluación de su desempeño. Con todo, los de la inseguridad y de la corrupción aparecen y permanecen durante los dos sexenios como temas que se mantienen en la ecuación de la aprobación presidencial. 


\section{APROBACIÓN PRESIDENCIAL}

Es fama que las mediciones de aprobación presidencial se utilizan para conocer cómo los ciudadanos evalúan la gestión gubernamental del presidente en turno. Altos niveles de popularidad presidencial pagan dividendos electorales tanto para el Presidente, como para su partido, ${ }^{1}$ a más de afectar sus objetivos de política, su estrategia legislativa y las probabilidades de triunfo en la promoción de su agenda. ${ }^{2}$

Por lo que toca a México, es interesante señalar el efecto de arrastre que hay entre la aprobación presidencial y la evaluación de otras agencias o entre aquélla y la política local. Por ejemplo, en nuestro estudio sobre los determinantes de la confianza ciudadana en el Instituto Federal Electoral (IFE), Ortega y yo ${ }^{3}$ hallamos que, en 2013 , la variable con mayor poder explicativo del grado de confianza de los ciudadanos en el INE, apenas por debajo de la confianza en los partidos y ser priista, es precisamente la aprobación del trabajo del presidente Peña Nieto.

${ }^{1}$ Véase P. Gronke, J. Koch y J. M. Wilson, "Follow the Leader? Presidential Approval, Perceived Presidential Support, and Representatives' Electoral Fortunes", Journal of Politics, vol. 65, núm. 3, 2003, pp. 785-808; B. Newman y C. W. Ostrom Jr., "Explaining Seat Changes in the US House of Representatives: 1950-1998", Legislative Studies Quarterly, vol. 27, núm. 3, 2002, pp. 383-405; y L. Sigelman, "Presidential Popularity and Presidential Elections”, Public Opinion Quarterly, vol. 43, núm. 4, 1979, pp. 532-534.

${ }^{2}$ Véase R. Brody, Assesing the President: The Media, Elite Opinion, and Public Support, Stanford, CA, University Press, 1991; P. Brace y B. Hinckley, Follow the Leader: Opinion Polls and the Modern Presidents, Nueva York, Basic Books, 1992; S. Kernell, Going Public: New Strategies of Presidential Leadership, Washington, DC, Congressional Quarterly Press, $3^{\mathrm{a}}$ ed., 1997; G. King y L. Ragsdale, The Elusive Executive, Washington, DC, Congressional Quarterly Press, 1988; B. Canes-Wrone y K. W. Shotts, "The Conditional Nature of Presidential Responsiveness to Public Opinion", ponencia presentada en la Annual Meeting of the Midwest Political Science Association, Chicago, 2002.

${ }^{3}$ Véase R. Ortega y Ma. Fernanda Somuano, Confianza y cambio político en México: contiendas electorales y el IFE, México, El Colegio de México, 2015. 
En lo que atañe a la política local, es plausible pensar que la aprobación en grado mínimo del presidente Peña Nieto pudo haber perjudicado a su partido durante la elección del Estado de México. Creo no errar en mi aserto, si se observa que los niveles de aprobación del gobernador de ese estado, a dos meses de celebrarse la elección, eran casi del $50 \%$, mientras que la intención de voto por el PRI era aproximadamente del 20. Es lícito pensar que los niveles de aprobación del presidente Peña Nieto, los cuales oscilaban para entonces entre el 30 y el 22\%, pudieron haber presionado la intención de voto por el PRI a la baja. ${ }^{4}$

Distintos estudios han documentado la enorme cantidad de actividades encaminadas a aumentar los niveles de popularidad del titular de la Presidencia. Los presidentes viajan para incrementar su popularidad, ${ }^{5}$ los discursos se dan estratégicamente para afectar la popularidad ${ }^{6}$ e incluso las políticas se diseñan e implementan no sin tener en mente los costos o beneficios que pueden tener en los índices de popularidad presidencial. En un estudio interesante, Ostrom y Simon ${ }^{7}$ apuntan que el éxito del Presidente en sus negociaciones

${ }^{4}$ Según datos de una encuesta de El Universal (10.IV.2017), la aprobación de Eruviel Ávila era del 50.4\%. En una encuesta semejante del Reforma (25.IV.2017), esa cifra era del 53\%. Sin embargo, en la misma encuesta, El Universal registró un nivel de aprobación para Peña del 30\%, mientras que el Reforma, para el mismo asunto, reportó el 22\%. Por lo demás, las cifras de intención de voto por el PRI en el Estado de México nunca fueron superiores al $25 \%$, una vez que se conocieron los candidatos a la gubernatura del estado, lo cual permite inferir que la aprobación del presidente pesaba más que la del gobernador sobre la intención de voto de los ciudadanos.

${ }^{5}$ Cf. D. M. Simon y C. W. Ostrom Jr., "The Impact of Televised Speeches and Foreign Travel on Presidential Approval", Public Opinion Quarterly, vol. 53, núm. 1, 1989, pp. 58-82, además de P. Brace y B. Hinckley, "Presidential Activities from Truman through Reagan: Timing and Impact", Journal of Politics, vol. 55, núm. 2, 1993, pp. 382-398.

${ }^{6}$ L. Ragsdale, "The Politics of Presidential Speechmaking, 19491980”, American Political Science Review, vol. 78, núm. 4, 1984, pp. 971-984.

7 "Promise and Performance: A Dynamic Model of Presidential Popularity", American Political Science Review, vol. 79, núm. 2, 1985, pp. 334-358. 
con el legislativo lleva a su vez a posteriores incrementos en la popularidad presidencial.

Subyacen en cada dato de aprobación o desaprobación razones o argumentos que dan cuenta de la opinión que tienen los gobernados sobre sus gobernantes. Algunos se basan en datos económicos o de seguridad, en tanto que otros se sustentan en la forma en la que se procesan algunas decisiones de gobierno (programas, planes de acción, decisiones en asuntos controvertidos, imagen pública), en la identificación con los partidos políticos o incluso en cuestiones ideológicas.

Académicos y expertos han dedicado no poca de su atención a tratar de explicar la dinámica detrás de la opinión pública y la aprobación presidencial. La investigación sobre aprobación presidencial constituye uno de los esfuerzos que más se ha multiplicado en la Ciencia Política. La gran mayoría de ese trabajo se ha concentrado en analizar tendencias de aprobación con datos agregados, ${ }^{8}$ es decir documentar la importancia causal de asuntos como la economía, la guerra y la cobertura de medios en la formación de la opinión ciudadana sobre el desempeño del Presidente.

Una de las formas más comunes de tratar el tema es la de comparar el aumento y la caída en la tasa de aprobación presidencial (tenida por variable dependiente) a lo largo del tiempo, de un lado, con el aumento y la caída de posibles variables explicativas, de otro, como el desempleo y la inflación. Un estudio de esta naturaleza tiene por hecho no puesto a discusión que, según cambian las circunstancias a que los individuos están supeditados, los niveles de apoyo para el Presidente habrán de cambiar ineluctablemente. Si la inflación y la aprobación varían conjuntamente, entonces el investigador concluiría que la tasa de inflación es parte de la explicación de los niveles de aprobación presidencial. Empero, el problema de basar la explicación del nivel de aprobación presiden-

${ }^{8}$ P. Gronke y B. Newman, "FDR to Clinton, Mueller to? A Field Essay on Presidential Approval", Political Research Quarterly, vol. 56, núm. 4, 2003, pp. 501-512. 
cial en datos agregados como la tasa de inflación o el índice de precios al consumidor es que sólo permite responder parcialmente la pregunta. La razón es que este tipo de datos no provee información sobre el comportamiento individual. Gronke y Newman señalan, con respecto de los estudios que se han hecho para explicar tendencias con datos agregados, que "es sorprendente... que se sepa tan poco sobre los determinantes individuales de la aprobación presidencial". 9

A finales de los ochenta y principios de los noventa, la bibliografía sobre la aprobación presidencial vivió una suerte de renacimiento, que fue la respuesta a un nuevo enfoque sobre opinión pública, ${ }^{10}$ el cual atendió especialmente los esfuerzos específicos de políticos, partidos y élites para moldear y cambiar las actitudes y el comportamiento políticos de los ciudadanos.

La bibliografía que sobre la aprobación presidencial se basa en datos individuales se concentra en distintas visiones de cómo los individuos conectan sus percepciones sobre la economía con la evaluación del titular del Ejecutivo. Un lado argumenta que el público, en el agregado, actúa de manera sofisticada al castigar o premiar a los presidentes, basándose en sus expectativas de desempeño económico futuro; ${ }^{11}$ otro, que el público evalúa condiciones pasadas y presentes para castigar o premiar al Presidente. ${ }^{12}$

9 "FDR to Clinton, Mueller to? A «State of the Discipline» Review of Presidential Approval", ponencia presentada en la Annual Meeting of the American Political Science Association, Washington, DC, agosto 31-septiembre 3, 2000, p. 22.

${ }^{10}$ P. Sniderman, "The New Look in Public Opinion Research", en A. Finifter (ed.), Political Science: The State of the Discipline II, Washington, DC, American Political Science Association, 1993, pp. 219-246.

${ }^{11}$ M. MacKuen et al., "Peasants or Bankers? The American Electorate and the U.S. Economy", American Political Science Review, vol. 86, núm. 3, 1992, pp. 596-611.

${ }^{12}$ H. Norpoth, "Presidents and the Prospective Voter", Journal of Politics, vol. 58, núm. 3, 1996, pp. 776-792; H. D. Clarcke y M. C. Stewart, "Prospections, Retrospections, and Rationality: The «Bankers» Model of 
Además de tomar en cuenta la economía y los eventos que automáticamente suscitan que se apoye al Presidente, diferentes estudios incorporaron las bases del comportamiento individual y corroboraron que las condiciones económicas y las percepciones afectan la aprobación presidencial, al igual que la forma en la que los presidentes lidian con crisis nacionales e internacionales. ${ }^{13}$

La bibliografía sobre la aprobación presidencial en México no ha sido abundante ${ }^{14}$ y la mayoría ha destacado las variables económicas como las más importantes en la evaluación del Presidente, en especial hasta el 2006. Buendía (art. cit.) muestra, por ejemplo, que durante los años que corrieron de 1988 a 1993, cuando las condiciones económicas mejoraron -en especial, la tasa de inflación anual, los salarios reales per capita en el sector manufacturero y la tasa de desempleo urbano-, el público apoyaba al Presidente y que, cuando la economía, por el contrario, se deterioró, le dio la espalda.

El artículo de Davis y Langley ${ }^{15}$ apunta que la variable económica -en este caso, la recuperación de la crisis econó-

Presidential Approval Reconsidered", American Journal of Political Science, vol. 38, núm. 4, 1994, pp. 1104-1123.

13 S. Greene, The Role of Character Assessments in Presidential Approval", American Politics Research, vol. 29, núm. 2, 2001, pp. 196-210; G. C. Edwards III y T. Swenson, "Who Rallies? The Anatomy of a Rally Event", Journal of Politics, vol. 59, núm. 1, 1997, pp. 200-212; M. Peffley et al., "Public Responses to the Presidential Use of Military Force: A Panel Analysis", Political Behavior, vol. 17, núm. 3, 1995, pp. 307-337.

${ }^{14}$ Aquí se pueden mencionar los trabajos de J. Buendía, "Economic Reform, Public Opinion, and Presidential Approval in Mexico, 19881993”, Comparative Political Studies, vol. 29, núm. 5, 1996, pp. 566-591; A. Moreno, Confianza en las instituciones: México en perspectiva comparada, México, CESOP-Cámara de Diputados LXI Legislatura, 1997, y, más recientemente, los de V. Romero, Impacto de la evaluación de políticas públicas en la evaluación presidencial, tesis, México, Instituto Tecnológico Autónomo de México (IтAм), 2000, e "Impacto de los temas de seguridad pública en la aprobación presidencial”, Política y gobierno, vol. temático: Desafíos de la política mexicana, 2013, pp. 139-160.

15 "Presidential Popularity in a Context of Economic Crisis and Political Change: The Case of Mexico", Studies in Comparative International Development, vol. 30, núm. 3, 1995, pp. 24-48. 
mica- no siempre es suficiente para que se incremente la popularidad del Presidente, pues sus datos muestran que entre 1986 y 1991 los mexicanos tomaron en cuenta también la Reforma Política y el tema de la corrupción para evaluar al Presidente.

En México, según Ulises Beltrán, “todos los estudios de votantes coinciden en destacar la importancia de las percepciones sobre el estado de la economía en la elección entre el partido en el poder y la oposición”. ${ }^{16} \mathrm{El}$ autor sugiere que la popularidad de los gobernantes está ligada al desempeño de la economía o, por mejor decir, a la percepción que tengan las personas sobre el desempeño económico nacional.

Es fuerza preguntarse, pese a todo, por qué habría de esperarse que sólo la economía influya en el juicio de los ciudadanos al momento de evaluar el trabajo del Presidente Es claro que el escenario económico de un país tiene un efecto directo en la situación económica personal de los individuos. Alta inflación, alta volatilidad en el tipo de cambio, alta tasa de desempleo son factores que afectan muy claramente la vida de un ciudadano. Sin embargo, hay otros factores que también afectan de manera directa, y a veces irreversible, la vida de un individuo. La inseguridad, por ejemplo, puede afectar a un ciudadano al poner en riesgo su negocio, su propiedad y, aún más, su integridad física o la de su familia.

Romero (art. cit.), primero, y Romero, Magaloni y DíazCalleros, ${ }^{17}$ después, analizan la relación entre distintas dimensiones de seguridad pública y la aprobación del presidente Calderón. Entre sus hallazgos, destacan que las evaluaciones económica y de seguridad son las variables que más efecto tienen en la probabilidad de evaluar en forma positiva o negativa al Presidente. El acuerdo con la estrategia del Presidente

16 "Aprobación presidencial: ¿’honestidad o eficiencia económica?", Nexos (en línea), junio de 2015, en http:/ / www.nexos.com.mx/?p=24988.

17 "Presidential Approval and Public Security in Mexico's War on Crime", Latin American Politics and Society, vol. 58, núm. 2, 2016, pp. 100-123. 
tiene también un efecto relativamente grande sobre la probabilidad de evaluar en forma positiva su trabajo.

El caso de la corrupción merece atención, porque mientras que en algunos países puede ser un tema meramente coyuntural (escándalos específicos de corrupción), en países como México puede considerarse parte de la vida cotidiana de un ciudadano. ${ }^{18}$ Según datos de LAPOP (2016-2017), el mexicano promedio considera que la corrupción es una práctica habitual entre los funcionarios públicos, es decir que poco menos del $80 \%$ cree que más de la mitad (o todos) los funcionarios públicos están involucrados en actos de corrupción. Asimismo, casi el 30\% de la población encuestada respondió haber experimentado al menos una instancia de corrupción. ${ }^{19}$ Por tanto, es plausible considerar que en el caso de México, ésta debiera ser un factor que el ciudadano tiene en cuenta, cuando evalúa a las autoridades y, en especial, al Presidente. Sin embargo, no pude identificar estudios que incluyan la corrupción como un factor que influya en la aprobación presidencial en México. En el estudio que aquí ofrezco incluí esa variable. ${ }^{20}$

${ }^{18}$ Por ejemplo, en el año 2016, el país se ubicó en el lugar 123 de 175 países evaluados en el Índice de Percepción de la Corrupción en el sector público -una medida entre 0 (muy corrupto) y 100 (muy transparente). México obtuvo una calificación de 30 y ha sido catalogado como uno de los 70 países más corruptos del mundo, así como el más corrupto de los 34 países de la OCDE.

${ }^{19}$ D. Zizumbo-Colunga y B. Amador, "Corupción en México", en V. Romero, P. Parás, G. Pizzolito y E. Zechmeister (eds.), Cultura política de la democracia en México y en las Américas, 2016-2017, México, USAID-LAPOP, 2018, pp. 93-113.

${ }^{20}$ Con el propósito de comprobar si la inseguridad y la corrupción pueden considerarse variables que influyen de manera sistemática en la evaluación de los presidentes en México, hice un análisis de correlación entre manejo de la economía, inseguridad, corrupción e intención de voto. Como puede verse en el apéndice 2 , hay una clara correlación significativa, estadísticamente, entre las tres variables y la intención de voto que se mantiene en 2008, 2010 y 2014. 


\section{RELEVANCIA DE TEMAS Y PRIMING}

Otros estudios que exploran las dinámicas detrás de la aprobación presidencial a nivel individual ${ }^{21}$ han tratado de analizar cómo la cobertura de medios puede influir en las evaluaciones que los individuos tienen del Presidente. ${ }^{22}$

La investigación, tanto en psicología como en ciencia política, ha encontrado que las actitudes que la gente expresa cuando responde a preguntas provenientes de encuestas reflejan las ideas que están en ese momento disponibles en su cabeza. ${ }^{23}$

Según la hipótesis del media priming (posicionamiento de temas por los medios), se acepta que las cargas cognitivas de los individuos para poder emitir juicios o tomar decisiones no se basan en información comprehensiva e integrada, es decir que el público, por el contrario, toma atajos cognitivos, basados en los temas que los medios posicionan. La familiaridad que los individuos tienen con temas políticos se

${ }^{21}$ Cf. D. C. Mutz, "Contextualizing Personal Experience: The Role of the Mass Media”, Journal of Politics, vol. 56, núm. 3, 1994, pp. 689-714; G. C. Edwards III et al., "Explaining Presidential Approval: The Significance of Issue Salience", American Journal of Political Science, vol. 39, núm. 1, 1995, pp. 108-134.

${ }^{22}$ Cf. S. Iyengar y D. R. Kinder, News that Matters, Chicago, University Press, 1987.

${ }^{23}$ Véase Tory E. Higgins y G. King, "Accessibility of Social Constructs: Information-Processing Consequences of Individual and Contextual Variability", en N. Cantor y J. Kihlstrom (eds.), Personality, Cognition, and Social Interaction, Hillsdale, NJ, Erlbaum, 1981; S. E. Taylor y S. Fiske, "Salience, Attention, and Attribution: Top of the Head Phenomena", en L. Berkowitz (ed.), Advances in Social Psychology, Nueva York, Academic Press, 1978, pp. 249-288; A. Tesser, "Self-Generated Attitude Change", en L. Berkowitz (ed.), Advances in Social Psychology, Nueva York, Academic Press, 1978, pp. 289-338; A. Tversky y D. Kahneman, "The Framing of Decisions and the Psychology of Choice", en Robin Hogarth (ed.), Question Framing and Response Consistency, San Francisco, Jossey-Bass, 1982; J. Zaller y S. Feldman, "A Simple Theory of the Survey Response: Answering Questions versus Revealing Preferences", American Journal of Political Science, vol. 36, núm. 3, 1992, pp. 579-616. 
relacionada con la cantidad y tiempo que estos asuntos reciben de los medios masivos. ${ }^{24}$ Así, los medios influyen en los temas que el público tiene por importantes, ${ }^{25}$ esto es los medios de comunicación eligen los temas que se consideran noticias y la importancia que deben tener (agenda setting) y el contenido informativo sugiere a la audiencia que debe usar rasgos o características específicas para evaluar el desempeño de sus líderes (priming). ${ }^{26}$ Así, la cobertura de medios de ciertos temas incrementa su importancia en la evaluación pública de determinadas figuras políticas. Según Iyengar, ${ }^{27}$ los temas que se repiten en las noticias de televisión se vuelven la prioridad para los televidentes. Temas y eventos destacados por las noticias se vuelven particularmente influyentes como criterios para evaluar a los funcionarios públicos.

En la bibliografía norteamericana, por ejemplo, se ha estudiado el tema de la guerra como un asunto que los ciudadanos valoran, cuando evalúan al Presidente. De acuerdo con el artículo arriba citado de Edwards, Mitchel y Welch, para que un asunto tenga influencia significativa en las evaluaciones presidenciales precisa de ser relevante para los individuos, quienes deben evaluar al Presidente según se haya desempeñado en tal asunto.

M. Singer descubrió en un estudio comparado de diferentes países (véase infra Bibliografía) que la importancia otorgada por los ciudadanos al tema económico disminuye cuando perciben crisis en otras áreas gubernamentales (guerras,

${ }^{24}$ B. I. Page y R. Y. Shapiro, The Rational Public, Chicago, University Press, 1992.

${ }^{25}$ S. Iyengar et al., "Experimental Demonstrations of the «Not-SoMinimal» Consequences of Television News Programs", American Political Science Review, vol. 76, núm. 4, 1982, pp. 848-858; M. B. MacKuen y S. L. Coombs, More than News, Beberly Hills, Sage, 1981.

${ }^{26}$ C. D. Anderson, y L. B. Stephenson (eds.), Voting Behaviour in Canada, Vancouver, UBC Press, 2010; D. Scheufele y D. Tewksbury, "Framing, Agenda Setting and Priming: The Evolution of Three Media Effects Models", Journal of Communication, vol. 57, núm. 1, 2007, pp. 9-20.

27 Is Anyone Responsible? How Television Frames Political Issues, Chicago, University Press, 1991. 
escándalos de corrupción, crisis de derechos humanos). Si no hubo errado con este aserto, la manera en que los ciudadanos se informan de esas situaciones o esos temas es por los medios de comunicación, especialmente la Televisión, la Radio y la Prensa (y, más recientemente, el Internet). Puede argumentarse, en dado caso, que los medios establecen los temas de la agenda pública; los ciudadanos los retoman y, muy probablemente, los tienen en la cabeza, cuando evalúan el trabajo del Presidente o de algún otro funcionario público.

Aunque no pretendo comprobar aquí empíricamente este modelo, analizo, en cambio, si los temas que prevalecieron en los medios dos meses antes que se levantaran las encuestas que uso en este estudio coinciden con aquellos que los ciudadanos percibieron como los más importantes. Puede inferirse, de ahí, que los ciudadanos, cuando evalúan el desempeño presidencial, toman en cuentan tales temas.

\section{Los niveles de aprobación de Felipe Calderón y ENRIQUe PeÑa Nieto}

Las coyunturas que enfrentaron Calderón y Peña Nieto durante sus gestiones fueron, a todas luces, muy distintas. El primero comenzó su gobierno con una grave crisis de legitimidad derivada de una elección muy competida, que ganó con un margen mínimo; el segundo, cuya elección también enfrentó cuestionamientos, con niveles de aceptación mucho más altos que su antecesor. La suscripción del Pacto por México, por lo demás, significó un reconocimiento para el presidente Peña Nieto, ya que se lo percibía como alguien que había sido capaz de conseguir acuerdos políticos para que se cumplieran once de las Reformas Estructurales que aún estaban pendientes o inconclusas hacía no pocos lustros.

Cómo fue que se movieron los niveles de aprobación de Calderón durante su mandato, cabría preguntarse en este punto, y cuáles han sido los de Peña Nieto en lo que va de su gobierno. Aunque las mediciones varían según la casa encues- 
tadora, en un poll de polls (promedio de diversas encuestas: Buendía \& Laredo; Parametría; GEA-ISA; Consulta Mitofsky) se puede observar que, en el caso de Calderón, la aprobación se mantuvo en un rango de entre el 44 y $68 \%$. Aun cuando los ciudadanos se volvieron más críticos sobre la violencia que asolaba el país, daban buenas calificaciones a su gestión en general, a causa, muy probablemente, de los niveles de estabilidad económica que vivimos por entonces (se registró la inflación más baja de la historia y hubo una acumulación histórica de reservas internacionales).

Los puntos más bajos de la aprobación de Calderón estaban cerca del 50\% en el pasaje del 2010 al 2011. Estas bajas parecen estar asociadas a percepciones sobre los niveles que alcanzó la violencia en México en ese punto y a la incapacidad del Gobierno para hacerle frente.

Peña Nieto, quien inició su mandato con una aprobación del $55 \%$ y tuvo un repunte a lo largo de 2013, en noviembre y diciembre de ese mismo año bajó al 53\% para caer luego a niveles de entre el 29\% (según Consulta Mitofsky, agosto de 2016) y el 25\% (Buendía y Laredo, noviembre del 2016). Estos porcentajes representan la calificación más baja para un presidente desde que se inició la publicación de encuestas similares en 1995 (Reforma, 13.IV.16). La caída más pronunciada comenzó en febrero de 2014 y parece coincidir con las evaluaciones más bajas de los ciudadanos sobre las Reformas Estructurales (en especial, las Reformas Energética y Fiscal provocaron el mayor número de evaluaciones negativas). De entonces en más, se ha ido deteriorando el porcentaje de los encuestados que aprueban su trabajo. Según las cifras de Consulta Mitofsky, esta caída se debió en parte al crecimiento de la preocupación ciudadana por la inseguridad. En agosto del 2013, el 30\% de la población consideró, en efecto, que ése era el mayor problema; un año después, el porcentaje bajó al 27\% y se posicionó en el $26 \%$ en agosto del 2015. Un año después, subió al $31 \%$, pero, aunque parezca que fue alta, en los últimos años de Calderón, llegó al 37\%. 


\section{GRÁFICA 1}

Niveles de aprobación y desaprobación de Felipe Calderón

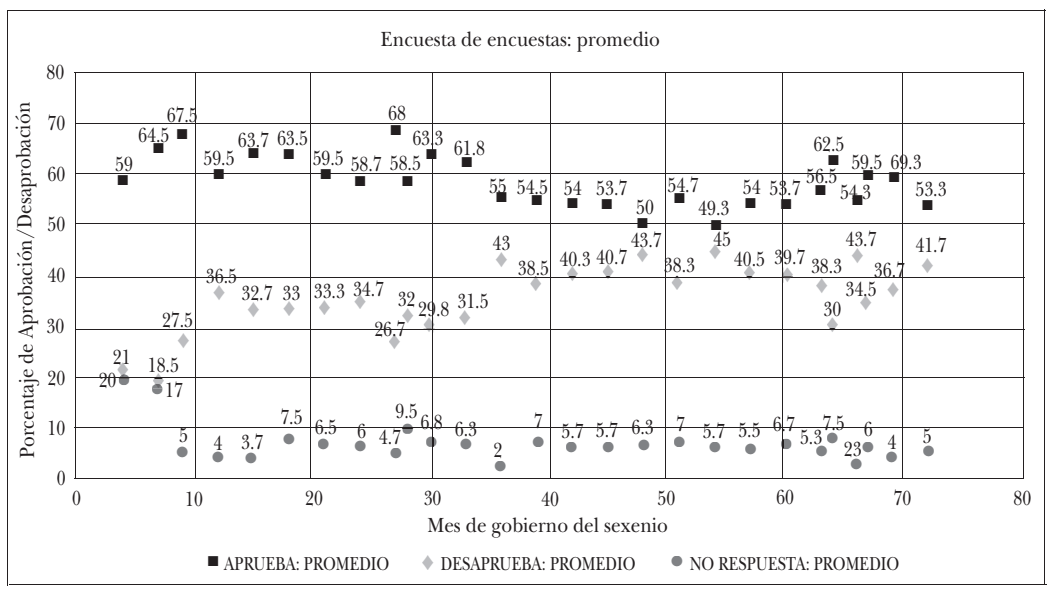

Como mencioné anteriormente, el nivel de aprobación de un presidente es importante, porque está relacionado con la legitimidad y el margen de maniobra con el que cuenta a lo largo de su mandato. Ahora bien, para conocer qué factores determinaron la evaluación positiva o negativa de los dos presidentes analizados aquí, es importante conocer el contexto en el que se levantaron las encuestas que utilizo en esta investigación, con el fin de tener en cuenta sesgos potenciales en las respuestas de los ciudadanos ocasionados más por coyunturas específicas (fuertes crisis económicas, estallamiento de conflictos armados, eventos políticos graves) que por cuestiones más estructurales de la evaluación presidencial en tiempos "normales". ${ }^{28}$

En ambos casos, las encuestas se llevaron a cabo cuando cada presidente iniciaba el segundo año de su gestión, entre los meses de enero y febrero, 2008 y 2014, respectivamente. La selección de los años 2008 y 20014, más allá de

${ }^{28}$ Cf. Romero, art. cit. 
que fueron años en que había encuestas comparables disponibles, tiene que ver con las siguientes razones. En los meses de enero y febrero del 2008, no parecen haber noticias particularmente destacadas que pudieron haber ocasionado sesgos importantes en las percepciones de los ciudadanos con respecto del Presidente y su desempeño. Son años en los que la situación económica era relativamente estable, por lo que puede evaluarse mejor el peso real de los asuntos económicos en las evaluaciones de la gente, pues la variable económica gana importancia en situaciones de crisis, hiperinflación, decrecimiento económico, volatilidad.${ }^{29} \mathrm{El}$ segundo, por lo demás, es un año en que el presidente en turno ya debería de haber presentado su agenda de gobierno e implementar algunas medidas iniciales.

En enero de 2008, inicia el periodo de Juan Camilo Mouriño como secretario de Gobernación, quien tuvo que negociar con maestros de la sección 22 del magisterio que renovaron su protesta en contra de la ley del Issste y de la criminalización de la protesta social. Hacia mediados del mes de enero, las bajas temperaturas habían causado la muerte de 29 personas. El 17 de enero, los gobiernos de Estados Unidos y México pusieron en marcha el Proyecto Gunrunner para impedir el tráfico de armamento hacia nuestro país. A principios de febrero, tras meses de intentos fallidos de acuerdo, el día seis, Leonardo Valdés Zurita toma posesión como consejero presidente del IFE y Marco Antonio Baños y Benito Nacif, como consejeros. El suceso acaso mediáticamente más importante fue la captura de Alfredo Beltrán Leyva, presunto operador del cartel de Sinaloa, liderado por el "Chapo" Guzmán.

${ }^{29}$ Véase M. M. Singer, "Who Says «It's the Economy»? Cross-National and Cross Individual Variation in the Salience of Economic Performance”, Comparative Political Studies, vol. 44, núm. 3, 2011, pp. 284-312, y "Economic Voting in an Era of Non-Crisis: The Changing Electoral Agenda in Latin America 1982-2010”, Comparative Politics, vol. 45, núm. 2, 2013, pp. 169-185. 
GRÁFICA 2

Niveles de aprobación y desaprobación de Enrique Peña Nieto

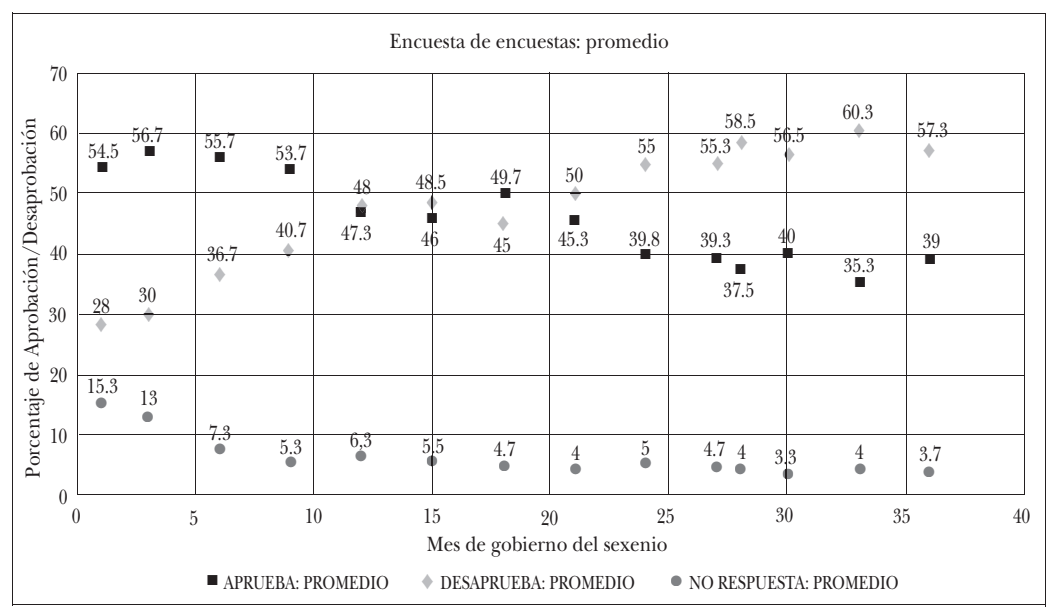

Con respecto de los meses de enero y febrero de 2014, sin duda, el hecho más mediático fue la captura de Joaquín Guzmán Loera, alias el "Chapo". Otras noticias relevantes en esos meses fueron la toma de Nueva Italia por las autodefensas en Michoacán y diversos enfrentamientos entre autodefensas y policía federal en la región de Tierra Caliente, Michoacán.

Hecho el balance de ambos periodos, las noticias que podrían haber tenido un efecto positivo fuera de lo común sobre la aprobación del Presidente serían la captura de los dos capos. Empero, como puede verse en las gráficas 1 (véase p. 644) y 2 , no parece haber saltos importantes alrededor de los meses 12 al 14 en los índices de popularidad de ambos presidentes, por lo que el efecto positivo potencial de dichas capturas parece diluirse.

Como puede verse en el cuadro 1 (p. 647), los datos de LAPOP muestran que la media de aprobación para Calderón al momento de levantarse la encuesta (febrero de 2008) es mayor que la de Peña Nieto (febrero de 2014). Asimismo, en 
los rubros de evaluación de desempeño relacionados con el combate a la corrupción, seguridad y desempleo/manejo de la economía, la media es mayor para Calderón que para Peña.

\section{CuAdro 1}

Niveles de aprobación de Felipe Calderón

y Enrique Peña Nieto

(Escala de evaluación del 1 al 5)

\begin{tabular}{ccccc}
\hline & Aprobación Calderón & Corrupción & Seguridad & Desempleo \\
\hline Media & 3.34 & 3.73 & 4.08 & 3.58 \\
Desviación estándar & .813 & 1.87 & 1.82 & 1.86
\end{tabular}

Aprobación Peña Nieto

Manejo de la economía

\begin{tabular}{ccccc} 
Media & 2.77 & 3.1 & 3.47 & 2.9 \\
Desviación estándar & 1.05 & 1.629 & 1.713 & 1.658 \\
\hline
\end{tabular}

Fuente: Elaboración propia con datos de LAPOP 2008 y 2014.

\section{Análisis empírico}

Teniendo como base la idea del priming de los medios y su potencial influencia sobre los ciudadanos, realicé una búsqueda hemerográfica ${ }^{30}$ en tres periódicos de circulación nacional

${ }^{30}$ La búsqueda se llevó a cabo en los siguientes periódicos: Reforma, $\mathrm{La}$ Jornada y El Universal. El análisis de contenido se hizo en dos etapas: la primera consistió en revisar las primeras planas de los tres diarios y clasificar las noticias por tema sin categorización previa; la segunda consistió en agrupar las noticias según el tema en categorías generales (tres preestablecidas: economía, inseguridad, corrupción; las demás se elaboraron con base en los temas de las propias notas que ocuparon la primera plana y que podían ser: cultura, deportes, política interna, asuntos internacionales, etc.). Así, en el rubro "Inseguridad", se incluyeron todas aquellas notas sobre narcotráfico, delincuencia, crimen; en el correspondiente a "Economía", todas las notas sobre inflación, desarrollo económico, pobreza, comercio, infraestructura, desigualdad; en el atinente a "Corrupción", todas las noticias relacionadas con corrupción en los tres niveles de gobierno. 
con el fin de detectar cuáles eran los temas que aparecían en la primera plana y los encabezados de cada diario. La revisión se hizo diariamente para el periodo que abarca dos meses y medio anteriores a la fecha del levantamiento de la encuesta (es decir del día primero de diciembre de 2007 al 31 de enero de 2008 y del primero de diciembre de 2013 al 31 enero de 2014). Idealmente, hubiera sido mejor hacer una revisión de los temas más mencionados en los noticiarios de televisión, pero desafortunadamente fue imposible encontrar los datos. Por tanto, hubo que sustituir esa información con datos provenientes de la prensa escrita, que plausiblemente tienen una influencia mucho menor en los ciudadanos. Sin embargo, di por hecho que los temas que aparecen en la primera plana de los diarios tienden a coincidir con los que destacan los noticieros de televisión. Además, según no pocas fuentes, el $27 \%$ de los mexicanos dijo haber leído un periódico, incluida la prensa en línea (IBOPE, datos del 2011, www.mediaperformance.ibopeagb.com.mx). A continuación, presento los temas que prevalecieron en la prensa en los dos momentos inmediatamente anteriores al levantamiento de las dos encuestas analizadas.

Es importante subrayar que el análisis de prensa muestra una coincidencia significativa entre los temas que aparecieron en primera plana en los diarios nacionales y los considerados por el público como los más relevantes. Como se aprecia en el cuadro 2, de la siguiente página, para el periodo de 2007-08, el tema económico (21\% de las noticias en primera plana), seguido de política interna (14\%) e inseguridad (13\%), fue el que más apareció en los tres diarios nacionales revisados. Para el periodo 2013-14, nuevamente el tema económico fue el que más apareció en dichos diarios $(23 \%)$, seguido por el tema de inseguridad (14\%) y el de asuntos internacionales (13\%). Los temas económicos y de seguridad fueron los que prevalecieron, tanto en titula-

Las categorías son excluyentes, por lo que una noticia sólo se contabiliza en una categoría. 
res como en encabezados de los tres diarios. Aunque los temas económicos tuvieron mayor cobertura que todos los demás temas en los tres diarios analizados, en La Jornada y El Universal la proporción de encabezados de seguridad sobre el total de titulares fue mayor que la de los temas económicos.

\section{Cuadro 2}

Aparición de temas en primera plana de tres diarios nacionales (dic-2007/ene-2008)

\begin{tabular}{lcccccccc}
\hline & $\begin{array}{c}E l \\
\text { Universal }\end{array}$ & $\%$ & $\begin{array}{c}\text { La } \\
\text { Jornada }\end{array}$ & $\%$ & Reforma & $\%$ & $\begin{array}{c}\text { Total } \\
\text { menciones }\end{array}$ & $\begin{array}{c}\text { Total } \\
\%\end{array}$ \\
\hline Economía & 52 & 18 & 79 & 16 & 104 & 32 & 235 & 21 \\
Política interna & 50 & 17 & 63 & 13 & 38 & 11 & 151 & 14 \\
Partidos políticos & 33 & 11 & 25 & 5 & 10 & 3 & 68 & 6 \\
Inseguridad & 48 & 16 & 45 & 9 & 47 & 14 & 140 & 13 \\
Mundo & 44 & 15 & 88 & 18 & 44 & 13 & 176 & 16 \\
Corrupción & 8 & 2 & 6 & 1 & 9 & 2 & 23 & 2 \\
Derechos Humanos & 5 & 1 & 36 & 7 & 11 & 3 & 52 & 5 \\
Energía & 6 & 2 & 27 & 5 & 4 & 1 & 37 & 3 \\
Ocio, deportes, cultura & 17 & 5 & 39 & 8 & 41 & 12 & 97 & 8 \\
Otros & 32 & 11 & 79 & 16 & 17 & 5 & 128 & 11 \\
Total noticias primera plana & 289 & & 487 & & 325 & & 1101 & \\
\hline
\end{tabular}

Nota: Las primera, tercera y quinta columnas presentan el número de noticias en primera plana seleccionadas por tema. Las segunda, cuarta y sexta, el porcentaje que representa el número de noticias entre el total de noticias en primera plana de cada diario.

Fuente: Elaboración propia.

En el cuadro 4, de la siguiente página, aparece el problema que la gente consideró como el más importante que enfrentaba el país en los dos momentos en los que las encuestas fueron levantadas. Claramente, la economía (nivel de inflación, desempleo, pobreza y desigualdad) fue el tema que más menciones recibió en ambas oleadas de la encuesta, seguido por los de inseguridad y corrupción. 


\section{Cuadro 3}

Aparición de temas en primera plana de tres diarios nacionales (dic-2013/ene-2014

\begin{tabular}{lcccccccc}
\hline & $\begin{array}{c}E l \\
\text { Universal }\end{array}$ & $\%$ & $\begin{array}{c}\text { La } \\
\text { Jornada }\end{array}$ & $\%$ & Reforma & $\%$ & $\begin{array}{c}\text { Total } \\
\text { menciones }\end{array}$ & $\begin{array}{c}\text { Total } \\
\%\end{array}$ \\
\hline Economía & 89 & 20 & 96 & 21 & 81 & 27 & 266 & 23 \\
Política interna & 38 & 9 & 57 & 12 & 31 & 10 & 126 & 11 \\
Partidos políticos & 12 & 3 & 15 & 3 & 10 & 3 & 37 & 3 \\
Inseguridad & 71 & 16 & 52 & 11 & 47 & 16 & 170 & 14 \\
Mundo & 35 & 8 & 97 & 21 & 21 & 7 & 153 & 13 \\
Corrupción & 25 & 5 & 11 & 2 & 29 & 9 & 65 & 5 \\
Derechos Humanos & 45 & 10 & 28 & 6 & 13 & 4 & 86 & 7 \\
Energía & 14 & 3 & 34 & 7 & 20 & 6 & 68 & 6 \\
Ocio, deportes, cultura & 50 & 12 & 47 & 10 & 22 & 7 & 119 & 10 \\
Otros & 46 & 11 & 12 & 3 & 25 & 8 & 83 & 7 \\
Total noticias primera plana & 425 & & 449 & & 299 & & 1173 & \\
\hline
\end{tabular}

Nota: Las primera, tercera y quinta columnas presentan el número de noticias en primera plana seleccionadas por tema. Las segunda, cuarta y sexta, el porcentaje que representa el número de noticias entre el total de noticias en primera plana de cada diario.

Fuente: Elaboración propia.

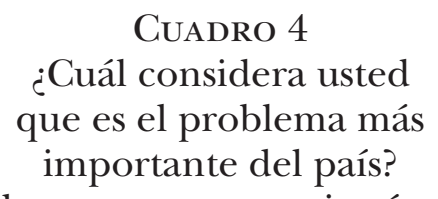

(Porcentaje de gente que mencionó ese problema)

\begin{tabular}{ccc}
\hline $\begin{array}{c}\text { Economía } \\
\text { (inflación, desempleo, pobreza, } \\
\text { desigualdad) }\end{array}$ & $\begin{array}{c}\text { Inseguridad } \\
\text { (delincuencia, crimen, narcotráfico, } \\
\text { falta de seguridad) }\end{array}$ & Corrupción \\
\hline \multicolumn{4}{c}{$27.7 \%$} \\
\hline $46.6 \%$ & 2008 & $5.9 \%$ \\
\hline $42.9 \%$ & 2014 & $8.3 \%$ \\
\hline
\end{tabular}

Fuente: Elaboración propia con datos de LAPOP 2008 y $2014 .{ }^{31}$

${ }^{31}$ Este dato subió a 9.46\% en LAPOP 2016-2017. 


\section{Análisis estadístico}

Conocidos cuáles son los problemas que los ciudadanos consideran los más importantes y cómo éstos coinciden o no con los que la prensa destaca, construí dos modelos estadísticos para intentar determinar los factores que influyen en la aprobación de los dos presidentes mencionados. Por las características de la variable dependiente con la que trabajo (variable ordinal discreta), decidí utilizar un modelo de regresión logística ordinal para cada presidente. ${ }^{32}$ Dado que las preguntas de ambas oleadas (2008 y 2014) tienen prácticamente el mismo fraseo y las mismas opciones de respuesta son iguales, con excepción de un par, la comparación puede hacerse casi de forma directa (véase el cuadro 5, p. 654, que ofrece los resultados de estos modelos).

Tomando en cuenta los temas que aparecieron más en el análisis hemerográfico antes mencionado y los que la ciudadanía consideró como los más importantes del país, incluí como variables independientes tres grupos de factores relacionados con la economía, la inseguridad y la corrupción para medir cuál es el efecto neto de estos temas en la aprobación presidencial y, en especial, para saber si el tema económico prevalece sobre los otros dos.

Como mencioné anteriormente, hay una vasta bibliografía sobre la influencia de la economía en los índices de aprobación presidencial, sobre todo en Estados Unidos. En el caso mexicano, estudios previos muestran cómo, en distintas elecciones, el tema económico tiene una influencia decisiva en el momento de decidir apoyar a un candidato. Los votantes que se muestran optimistas frente a la situación económica nacional tienen mayor probabilidad de apoyar

32 En este caso, el modelo supone la aprobación presidencial como variable latente. El modelo determina los puntos de corte para las cinco categorías de aprobación (cuatro cortes) y estima la probabilidad de observar cada resultado como el área bajo la curva entre un par determinado de puntos de corte. 
al presidente en turno. ${ }^{33}$ Claramente el tema económico tiene distintas dimensiones, por lo que su efecto en la aprobación presidencial debería diferenciarse por dimensión. Una primera dimensión es la evaluación que el individuo hace de la situación económica nacional (lo que en la bibliografía sobre voto económico se llama voto sociotrópico). Otra es la evaluación que hace el individuo de cómo le ha ido en sus finanzas personales (voto egotrópico). Hay otra dimensión, en fin, que se refiere a la evaluación general del desempeño del gobierno (Presidente) en el tema económico. ${ }^{34}$ Incluí, además, una variable que mide el grado de satisfacción ciudadana con los servicios públicos que recibe del municipio.

Tras la estela de esa bibliografía, las hipótesis propuestas son que quien evalúa mejor el manejo de la economía por parte del gobierno; quien considera que la situación económica del país es mejor que la de hace un año; quien considera que su situación económica personal mejoró con respecto al año anterior; quien está más satisfecho con los servicios públicos que recibe, tenderá a evaluar mejor al Presidente.

El tema de la seguridad pública y la violencia es una cuestión que debiera preocupar a los individuos, pues está relacionado con la protección de su integridad física por parte del Estado. En el caso de México, éste se volvió un problema muy grave a partir del segundo año de la presidencia de Felipe Calderón (según la Encuesta Nacional de Cultura Políti-

${ }^{33}$ Cf. Buendía, art. cit., y Singer, "«Defendamos lo que hemos logrado». El voto económico en México durante la elección presidencial de 2006", Política y gobierno, vol. temático: Elecciones en México, 2009, pp. 199-235.

${ }^{34}$ Debido a la probabilidad de que existiera un problema de multicolinearidad entre las tres dimensiones del tema económico, estimé distintas correlaciones parciales. En ningún caso dicha correlación fue mayor a .50. La correlación más alta entre las variables económicas para ambos presidentes fue la obtenida entre evaluación de situación económica del país y la personal, cuyo valor fue de .390 para Peña y .478 para Calderón. 
ca y Prácticas Ciudadanas, ENCUP, del 2003, el porcentaje de gente que dijo que el problema que más le preocupaba era del $20.9 \%$, es decir siete puntos porcentuales menos que en el 2008 y casi 15 puntos menos que en el 2014). Al igual que el tema económico, este tema también es multidimensional. ${ }^{35}$ En este modelo, introduzco tres dimensiones. La primera es la evaluación general del desempeño del Presidente en los temas de seguridad. La segunda, el impacto directo de la inseguridad en la vida del ciudadano, como su victimización o la de alguien en su familia. La tercera, la percepción que tiene el individuo de la inseguridad en su colonia o barrio. ${ }^{36}$ Se esperaría que a mejor desempeño en materia de seguridad corresponda un mayor nivel de aprobación presidencial; que quienes sienten mayor temor de ser víctimas en su barrio o quienes ya lo han sido sean menos propensos a evaluar positivamente al Presidente.

Por último, por lo que toca al tema de corrupción, introduje la evaluación de los individuos del desempeño del gobierno en el combate a la corrupción. Como variables de control incluí algunas características sociodemográficas del individuo que pueden tener algún efecto sobre sus valores y actitudes, especialmente la identidad partidista, asumiendo que hay una relación positiva entre identificarse con el partido del Presidente y calificarlo mejor.

La variable dependiente (aprobación presidencial) está medida en una escala de cinco categorías. El fraseo de la pregunta es el que sigue: "Y hablando, en general, del actual gobierno, ¿diría usted que el trabajo que está realizando el presidente Felipe Calderón/ Enrique Peña Nieto es muy malo/ malo/ ni bueno ni malo/ bueno/ muy bueno?" (escala del 1 al 5).

35 Cf. Romero, art. cit.

${ }^{36}$ Igualmente, revisé posibles problemas de multicolinearidad, pero no encontré ninguno. 


\section{Cuadro 5 \\ Modelo de regresión logística ordinal}

\begin{tabular}{|c|c|c|}
\hline & Calderón & Peña \\
\hline Corte 1 & $\begin{array}{c}-2.347 * * * \\
(.549)\end{array}$ & $\begin{array}{c}1.952 * * \\
(.396)\end{array}$ \\
\hline Corte 2 & $\begin{array}{l}-.448 \\
(.529)\end{array}$ & $\begin{array}{c}3.546^{* *} \\
(.402)\end{array}$ \\
\hline Corte 3 & $\begin{array}{c}2.455^{* *} \\
(.533)\end{array}$ & $\begin{array}{c}5.630^{* *} \\
(.419)\end{array}$ \\
\hline Corte 4 & $\begin{array}{c}5.692 * * \\
(.556)\end{array}$ & $\begin{array}{c}9.243^{* *} \\
(.489)\end{array}$ \\
\hline \multicolumn{3}{|c|}{ TEMA SEGURIDAD } \\
\hline $\begin{array}{l}\text { Evaluación del gobierno actual } \\
\text { en seguridad ciudadana }\end{array}$ & $\begin{array}{l}.113^{* *} \\
(.047)\end{array}$ & $\begin{array}{l}.253 * * \\
(.046)\end{array}$ \\
\hline Víctima & $\begin{array}{l}-.021 \\
(.147)\end{array}$ & $\begin{array}{c}.064 \\
(.122)\end{array}$ \\
\hline Percepción de inseguridad en su barrio & $\begin{array}{l}-.163^{* *} \\
(.062)\end{array}$ & $\begin{array}{l}-.058 \\
(.062)\end{array}$ \\
\hline \multicolumn{3}{|c|}{ TEMA ECONÓMICO } \\
\hline $\begin{array}{c}\text { Evaluación del gobierno actual en combate } \\
\text { al desempleo/manejo de la economía }\end{array}$ & $\begin{array}{l}.254 * * \\
(.044)\end{array}$ & $\begin{array}{l}.397 * * \\
(.042)\end{array}$ \\
\hline $\begin{array}{l}\text { Situación económica actual del país es mejor, } \\
\text { igual o peor que hace doce meses }\end{array}$ & $\begin{array}{l}.284^{* *} \\
(.071)\end{array}$ & $\begin{array}{l}.439 * * \\
(.100)\end{array}$ \\
\hline $\begin{array}{l}\text { Situación económica actual es mejor, } \\
\text { igual o peor que la de hace doce meses }\end{array}$ & $\begin{array}{l}.133^{*} \\
(.079)\end{array}$ & $\begin{array}{l}.189 * \\
(.086)\end{array}$ \\
\hline $\begin{array}{c}\text { Satisfacción } \\
\text { con servicios municipales }\end{array}$ & $\begin{array}{l}.319 * * \\
(.074)\end{array}$ & $\begin{array}{l}.244 * * \\
(.058)\end{array}$ \\
\hline \multicolumn{3}{|c|}{ TEMA CORRUPCIÓN } \\
\hline $\begin{array}{l}\text { Evaluación del Gobierno } \\
\text { en combate a la corrupción }\end{array}$ & $\begin{array}{l}.175^{* *} \\
(.040)\end{array}$ & $\begin{array}{l}.149 * * \\
(.043)\end{array}$ \\
\hline Identificación PAN & $\begin{array}{c}1.028^{* *} \\
(.169)\end{array}$ & $\begin{array}{l}-.415^{*} \\
(.200)\end{array}$ \\
\hline
\end{tabular}


CUADro 5 (conclusión)

\begin{tabular}{ccc}
\hline & Calderón & Peña \\
\hline Identificación PRI & .134 & $.849 * *$ \\
Identificación PRD & $(.185)$ & $(159)$ \\
& $-.890^{* * *}$ & -.247 \\
Edad & $(.235)$ & $(.058)$ \\
& -.003 & $.010^{*}$ \\
Sexo & $(.004)$ & $(.004)$ \\
& -.004 & .061 \\
Escolaridad & $(.107)$ & $(.102)$ \\
& .009 & $-.034^{* *}$ \\
Pseudo R & $(.014)$ & $(.013)$ \\
$\mathrm{N}=$ & .221 & .233 \\
\hline
\end{tabular}

Nota: El error estándar se consigna entre paréntesis.

*Estadísticamente significativo al .05

**Estadísticamente significativo al .01

Cuadro 6

Cambio marginal en la apro- Cambio marginal en la aprobación de Calderón, cuando, bación de Peña Nieto, cuando, todo constante, cada variable todo constante, cada variable pasa de su valor mínimo al pasa de su valor mínimo al máximo

\begin{tabular}{lcc}
\hline & Malo & Bueno \\
\hline Evaluación del gobierno & -9 & 30
\end{tabular}

en manejo de la economía

Satisfacción con servicios $\quad-7 \quad 26$

municipales

Situación económica actual $\quad-6 \quad 24$

del país

Evaluación del gobierno

en combate la corrupción

Identificación PAN

\section{máximo}

\begin{tabular}{lcc}
\hline & Malo & Bueno \\
\hline $\begin{array}{l}\text { Evaluación del gobierno } \\
\text { en manejo de la economía }\end{array}$ & -28 & 39 \\
$\begin{array}{l}\text { Evaluación del gobierno } \\
\text { en seguridad }\end{array}$ & -13 & 23
\end{tabular}

Situación económica actual $\quad-12 \quad 16$ del país

$\begin{array}{lllll}-6 & 22 & \text { Identificación PRI } & -11 & 15\end{array}$

$\begin{array}{lllll}-4 & 21 & \text { Evaluación del gobierno } & -12 & 13\end{array}$

en combate la corrupción 
Cuadros 6 y 7 (conclusión)

\begin{tabular}{|c|c|c|c|c|c|}
\hline & Malo & Bueno & & Malo & Bueno \\
\hline $\begin{array}{l}\text { Evaluación del gobierno } \\
\text { en seguridad }\end{array}$ & -4 & 15 & $\begin{array}{l}\text { Satisfacción con servicios } \\
\text { municipales }\end{array}$ & -.1 & 13 \\
\hline $\begin{array}{l}\text { Situación económica } \\
\text { personal actual }\end{array}$ & -3 & 11 & $\begin{array}{l}\text { Situación económica } \\
\text { personal actual }\end{array}$ & -5 & 5 \\
\hline $\begin{array}{l}\text { Percepción de inseguridad } \\
\text { en su barrio }\end{array}$ & -.3 & 10 & Víctima & -1 & 1 \\
\hline Identificación PRI & -1 & 3 & $\begin{array}{l}\text { Percepción de inseguridad } \\
\text { en su barrio }\end{array}$ & 2 & -2 \\
\hline Víctima & -.3 & 2 & Identificación PAN & 3 & -3 \\
\hline Identificación PRD & 8 & -17 & Identificación PRD & 5 & -4 \\
\hline
\end{tabular}

Fuente: Elaboración propia según los resultados del cuadro 5.

El cuadro 5 ofrece los resultados de los modelos de regresión logística ordinal para los dos presidentes. Los cuadros 6 y 7 , los efectos marginales de las variables del modelo en orden de mayor a menor influencia en la evaluación presidencial de las categorías mal desempeño y buen desempeño. Según se muestran los efectos marginales en los cuadros 6 y 7 , en ambos casos el tema económico, medido como la evaluación que los ciudadanos hacen del manejo de la economía por parte del gobierno, es la variable con el mayor efecto sobre el nivel de aprobación presidencial para ambos presidentes.

En las gráficas 3 y 4 (véanse pp. 657 y 658), se observa la magnitud y la forma del efecto de la evaluación ciudadana del manejo de la economía en la aprobación presidencial para cada presidente. Dicho efecto se estima mediante simulaciones de valores de aprobación en función de los distintos valores de la variable independiente, manteniendo todo lo demás constante. En ambas gráficas, se muestra que en las categorías intermedias (malo, ni bueno ni malo y bueno) se registra un impacto mayor de la evaluación del tema económico sobre la aprobación presidencial. En el caso del presidente Calderón, el efecto en la categoría "bueno" es que la probabilidad de aprobación aumenta en 30\%, al pasar de que el individuo opina que el gobierno no está haciendo "nada" para combatir el desempleo a la de está haciendo "mucho". Para el 
caso del presidente Peña Nieto el efecto es aún mayor, pues el aumento es de $39 \%$. En general los resultados del modelo confirman que los individuos que tienen una buena opinión del desempeño del gobierno en el manejo de la economía (medido como el combate al desempleo) evalúan mejor a ambos presidentes.

\section{GrÁfica 3}

Efectos del manejo en la economía en la aprobación de Calderón

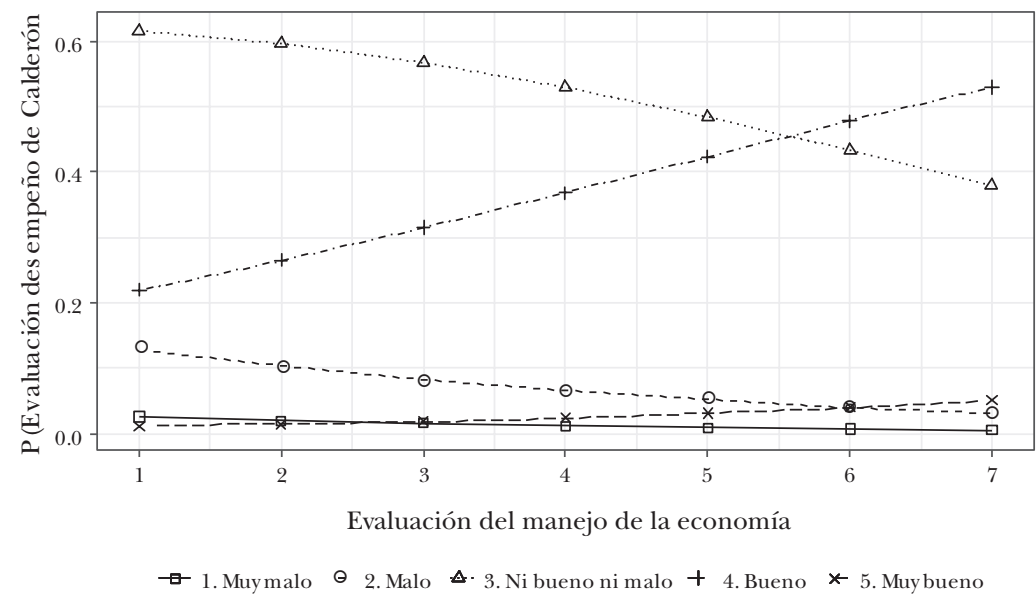

Reclama no poco la atención el efecto de la satisfacción con la calidad de los servicios municipales, sobre todo en la aprobación de Calderón, pues tiene un impacto muy importante (el segundo mayor sólo detrás de manejo de la economía). El efecto en la categoría bueno es que la probabilidad de aprobación aumenta en $26 \%$ al pasar de que el individuo considere que los servicios que da el municipio son "muy malos" a que considere que son "muy buenos". Este resultado es interesante, porque indica que hay ocasiones en las que los ciudadanos pueden evaluar el desempeño del Presidente, haciéndolo responsable de asuntos que no están entre sus atri- 
buciones o están fuera de su control. Claramente, cuando los ciudadanos piden cuentas al Presidente de un tema sobre el que éste no tiene poder o sobre el que tienen expectativas poco realistas, el Presidente se enfrenta a un problema.

\section{GrÁFICA 4}

Efectos del manejo en la economía en la aprobación de Peña Nieto

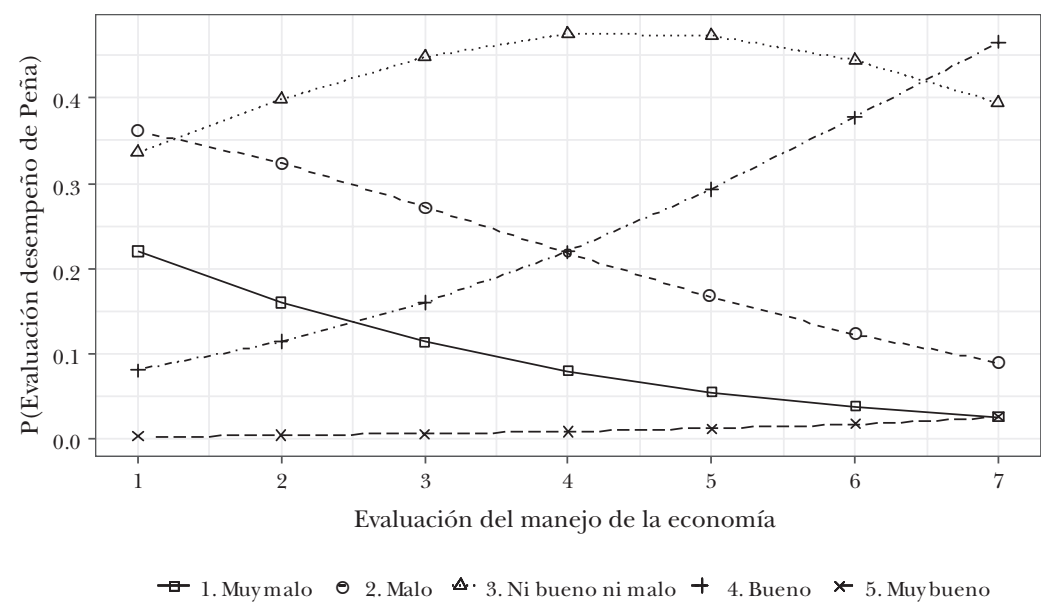

El impacto del tema de seguridad (que los ciudadanos mencionaron como el segundo más importante en el país) sobre el desempeño de los presidentes Calderón y Peña se muestra en las gráficas 5 y 6 , de la siguiente página. Los resultados de los modelos confirman la hipótesis de que a mejor evaluación del desempeño del gobierno en materia de seguridad hay una mayor aprobación ciudadana del Presidente. La seguridad es la segunda variable con mayor influencia sobre la aprobación de Peña Nieto. En cambio, el efecto en la de Calderón es mucho menor. Para este último, en el segmento de aprobación buena, el efecto del cambio en la probabilidad de aprobar al Presidente es de 15 puntos porcentuales al pasar de considerar que el trabajo del gobierno en seguridad la mejora nada a la de la mejora mucho. 


\section{GrÁfICA 5}

Efectos del manejo de la seguridad en la aprobación de Calderón

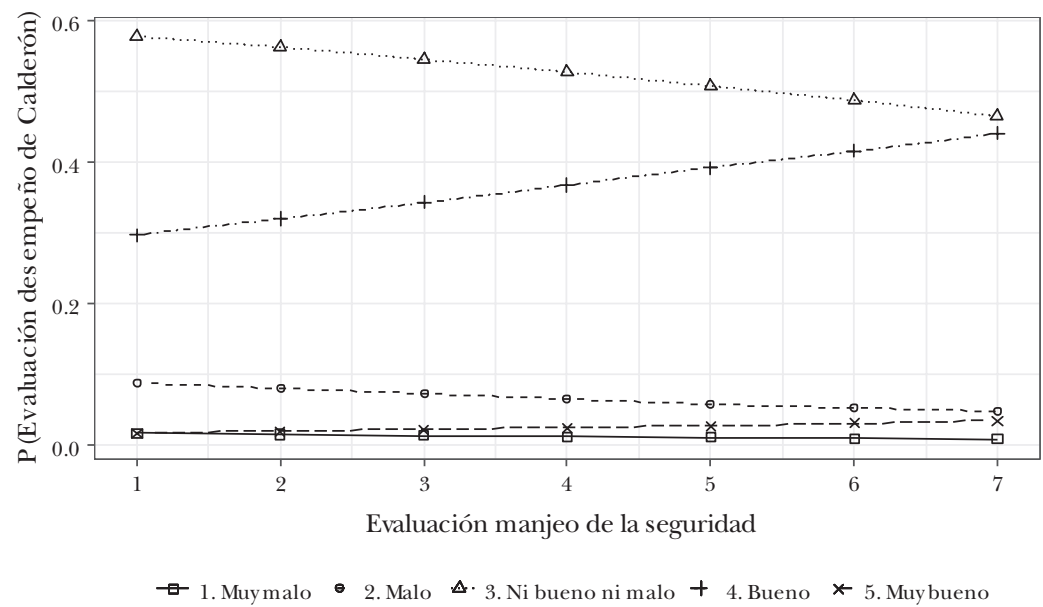

Gráfica 6

Efectos del manejo de la seguridad en la aprobación de peña Nieto

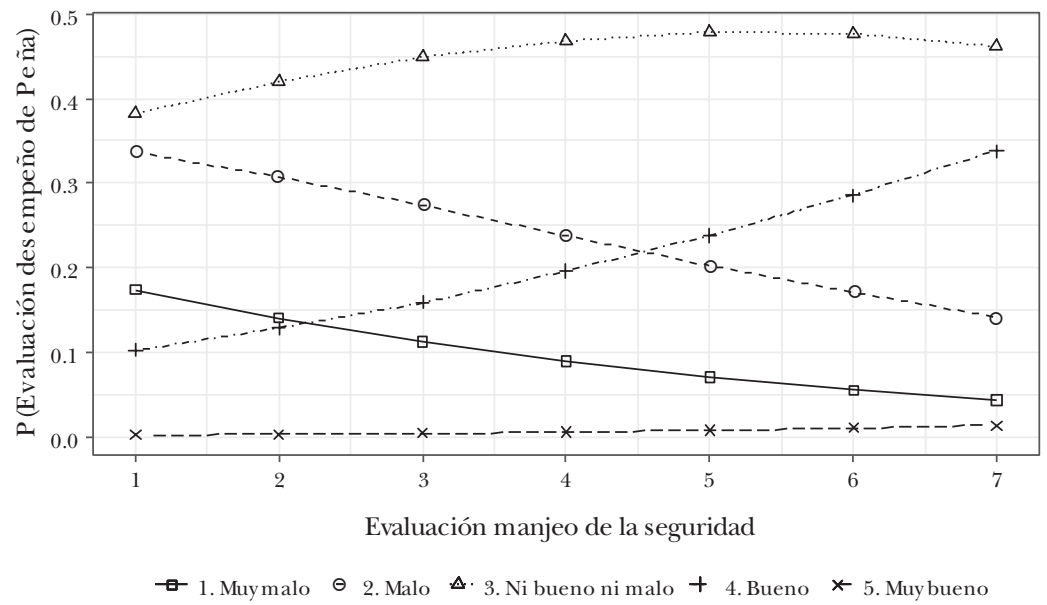


En el caso de Peña Nieto, en las categorías de aprobación malo y bueno, el impacto de la seguridad sobre su aprobación es muy alto. En el caso de la opinión positiva, la probabilidad de aprobación cambia del 10 al 33 \% (23 puntos porcentuales), cuando un individuo pasa de opinar que el trabajo del gobierno en seguridad la mejora nada, a la opinión de que la mejora mucho; en el caso de la opinión negativa (mala), el cambio es de menos 13 puntos porcentuales. Una posible razón del mayor impacto de la seguridad en la aprobación de Peña Nieto sobre la de Calderón puede estar relacionada con la cobertura noticiosa de la prensa. En ese sentido, es relevante mencionar que, aunque el tema con mayor cobertura en los diarios fue el económico, la proporción de encabezados de seguridad fueron más en el periodo de Peña Nieto que en el de Calderón (el doble, en dos de los tres diarios revisados).

Sorprende no poco que la victimización no tenga efecto sobre la variable dependiente, pues es plausible esperar que quienes han sido víctimas de un delito tenderían a evaluar de manera más negativa al Presidente, que quienes no lo han sido. Romero (art. cit.), quien encuentra el mismo resultado para 2010, argumenta que éste puede deberse a dos razones. La primera puede estar relacionada con un problema de medición; por ejemplo, que los encuestados hayan tenido temor de declarar que habían sido víctimas y, por tanto, la victimización se encuentra subrepresentada en la muestra de la encuesta.

La segunda razón podría consistir en que las víctimas no responsabilizan al Presidente de dicho suceso, porque hacen responsable a otro nivel de gobierno o porque, aun cuando sí responsabilizan al Gobierno federal o incluso al titular del Ejecutivo, consideran que éste está haciendo su mejor esfuerzo para combatir la delincuencia.

Con respecto de la segunda dimensión de seguridad que incluí en el modelo (la de percepción de inseguridad en el barrio) sólo fue significativa y negativa para el caso de Calderón, es decir que quienes mencionaron tener mayores percep- 
ciones de inseguridad en su colonia, también aumentaron sus probabilidades de evaluar de manera más negativa a Calderón.

Para ambos presidentes, la variable partidista tiene un efecto alto y significativo sobre la aprobación presidencial, lo cual se ajusta a las expectativas. Diversos estudios han mostrado cómo la identidad partidista afecta las percepciones y actitudes de los ciudadanos en diversos rubros. ${ }^{37}$ Quienes se identifican con el partido del Presidente tenderán a evaluarlo mejor que quienes simpatizan con partidos de la oposición o se consideran independientes o apartidistas. La probabilidad de aprobación en la categoría bueno aumenta el 21\% de quienes se identifican con el PAN para Calderón y $15 \%$ para quienes se identifican con el PRI para Peña Nieto. En el caso de la presidencia de Salinas, por ejemplo, Moreno ${ }^{38}$ halla un alto poder predictivo de la variable partidista en sus niveles de aprobación. Asimismo, Romero (art. cit.) encuentra un efecto de la variable partidista importante en los niveles de aprobación de Zedillo.

El tema de la corrupción, como se esperaba, también tuvo una influencia significativa sobre la aprobación de ambos presidentes, aunque menor a la de la economía y la seguridad. Más aún, ésta es mucho más fuerte en la aprobación de Calderón que en la de Peña. El cambio porcentual en la probabilidad de aprobación del primero es del 22\% (en la categoría de aprobación bueno), cuando la percepción de los ciudadanos sobre el manejo de la corrupción se mueve de no haber mejorado nada a la de mejoró mucho. En el caso de Peña Nieto, el cambio porcentual es de sólo 13\%. Nuevamente, este resultado puede estar relacionado con la cobertura que los medios dieron al tema. Algunos meses antes del levantamiento de la encuesta de Calderón (octubre 2007), la prensa publicó durante varios días un caso de corrupción que involucraba el

${ }^{37}$ Cf. por ejemplo, R. Ortega et al., "Partisan Identity and Democracy in the Mexican States", en S. Martí et al. (eds.), Democracy in Mexico. Attitudes and perceptions of citizens at national and local level, Londres, Institute of Latin American Studies, 2014.

${ }^{38}$ Moreno, op. cit. 
choque de la plataforma Usumacinta, propiedad de un contratista de PEMEx. Además de los 18 trabajadores fallecidos y la enorme mancha de crudo que contaminó las costas del Golfo de México, salieron a la luz las pésimas condiciones en las que laboraban los empleados de la paraestatal y la intimidación de PEMEX a los medios para evitar que difundieran la información sobre todas las irregularidades del caso. ${ }^{39}$ En cambio, en el caso de Peña Nieto, los escándalos de corrupción fueron publicados después del levantamiento de la encuesta analizada, por lo que es probable que por esa razón no hubiera impacto de esa variable en los niveles de aprobación de Peña Nieto.

La escolaridad, por lo demás, no tiene efecto sobre la aprobación de Calderón, pero sí lo tiene sobre la de Peña Nieto. En este segundo caso, encontramos que, a menor escolaridad, la probabilidad de evaluar positivamente a Peña aumenta, lo que confirma que los menos escolarizados tienden a ser menos críticos. Más allá de la escolaridad, las demás variables sociodemográficas no muestran un efecto significativo sobre la aprobación presidencial.

\section{Conclusiones}

En este trabajo, he intentado aportar elementos para entender qué factores toman en cuenta los ciudadanos, cuando evalúan en México al presidente en turno. Al comparar dos presidentes (de una parte, Felipe Calderón y, de otra, Enrique Peña Nieto, militantes de partidos políticos distintos, que gobernaron en coyunturas disímiles y en periodos de tiempo distintos), hallé que el tema económico prevalece como el más importante, cuando el ciudadano medio evalúa el desempeño del Presidente. Si revisamos los resultados del estudio de

${ }^{39}$ Cf. http:/ /www.jornada.unam.mx/2007/10/25/index.php?section =estados\&article=034n lest y http: / / archivo.eluniversal.com.mx $/$ notas $/ 45$ 7166.html. 
Villarrea ${ }^{40}$ y del ya citado de Buendía sobre la presidencia de Salinas, los estudios de Romero sobre Zedillo ${ }^{41}$ y Calderón, ${ }^{42}$ y los obtenidos en el presente estudio, todos parecen coincidir en que más allá de coyunturas específicas y de cualidades individuales de los presidentes, el factor más importante que el ciudadano toma en cuenta en la aprobación/desaprobación del Presidente es el económico. Es probable que esto se deba a la percepción de que la economía es lo que afecta de manera más directa la vida diaria de los ciudadanos. Sin embargo, la magnitud del efecto del tema económico sí varía sustantivamente para cada presidente. También los efectos de las demás variables cambian para cada uno de ellos. Descuella el caso de la satisfacción con los servicios municipales para Calderón y el tema de seguridad para Peña Nieto. Interesantemente, la satisfacción con los servicios municipales, un tema que no está entre las competencias del Presidente, es el factor que influyó más en la aprobación de Calderón, apenas si por encima del manejo de la economía. En cambio, el tema de seguridad ocupa el sexto puesto, aun cuando en la prensa sí se cubrió de manera sustantiva. Sin embargo, hay que tomar en cuenta que durante los meses del levantamiento de la encuesta que analizo, la violencia no llegaba a los picos que alcanzó a finales del 2010 y principios del 2012.

En el caso de Peña Nieto, el tema de seguridad sí aparece como el segundo factor que afecta su nivel de aprobación, sólo detrás de la economía, lo cual coincide con una mayor aparición de noticias en la prensa sobre seguridad en el periodo de Peña que en el de Calderón.

Mediante la búsqueda hemerográfica realizada, es posible suponer que hay una relación entre los temas que aparecen en la prensa escrita y los que los ciudadanos perciben como los más importantes para ellos, es decir que los temas

40 "Public Opinion of the Economy and the President during the Salinas Sexenio: The Role of Mass Media", documento preparado para la reunión de LASA en Washington, DC, septiembre de 1995.

${ }^{41}$ Romero, op. cit.

${ }^{42}$ Romero, art. cit., y Romero et al., art. cit. 
que los medios (en este caso, la prensa) posicionan como los más trascendentes coinciden de manera significativa con los que los ciudadanos tienen en mente, al hacer su evaluación del Presidente. En los dos periodos analizados en la prensa escrita, los temas más recurrentes fueron económicos, pues casi la mitad de los entrevistados mencionaron el tema económico como el más importante del país y, en consecuencia, fue al que más peso dieron al hacer su evaluación del presidente en turno.

Los otros dos temas mencionados por los ciudadanos como los más relevantes, que coincidentemente aparecieron de manera reiterada en las primeras planas de los diarios analizados, fueron seguridad y corrupción. Hay que notar, sin embargo, que los temas de política exterior y de política interna, que también tuvieron amplia cobertura en la prensa, no fueron mencionados como problemas relevantes para el país.

Por tanto, puedo afirmar que, aunque el tema económico sigue siendo preponderante, nuevos temas como la inseguridad y la corrupción se han posicionado como asuntos que los ciudadanos consideran cuando evalúan al Presidente. En el caso mexicano, en que la inseguridad y la corrupción han crecido de manera exponencial, pareciera que estos temas dejaron de ser coyunturales y ahora forman parte de la vida cotidiana de los ciudadanos. No es extraño entonces que tuvieran un efecto importante sobre la aprobación presidencial. Sería interesante analizar si en países con niveles bajos de inseguridad y corrupción, estos problemas se toman en cuenta al evaluar al Presidente, aunque es probable que no sea así. Así, este trabajo sugiere que los criterios que el ciudadano medio utiliza para evaluar al Presidente son una combinación entre los temas que los medios posicionan y sus propios valores y percepciones.

Las características demográficas de los individuos no mostraron efecto alguno sobre su evaluación, con excepción de la escolaridad y la edad en el caso de Peña Nieto. Como era de esperarse, la variable partidista es una lente importante con la que se evalúa al Presidente. Quienes son simpati- 
zantes del partido del Presidente tenderán a evaluarlo mejor que quienes se identifican con los partidos de oposición o se consideran independientes o apartidistas.

Quedan varias preguntas por responder, que ameritan nuevas investigaciones. Una de ellas se esbozó líneas arriba. $¿$ El presidente realmente puede moldear o influir sus niveles de aprobación? Como señalan Gronke y Newman, ${ }^{43}$ la respuesta que a esta pregunta se dé, ya positiva, ya negativa, tiene implicaciones importantes para la teoría democrática. En un mundo ideal, si mayor aprobación es equiparable a mayor poder, los ciudadanos deberían premiar al Presidente por cumplir con sus expectativas, lo que a su vez daría a éste incentivos para cumplir con esas expectativas. Sin embargo, si los ciudadanos exigen al Presidente resultados fuera de su alcance o tienen expectativas inviables, lo condenarían a una situación en que el ejercicio del poder sería muy complicado. De otra parte, si los presidentes tienen mucho control sobre sus niveles de aprobación, podrían incrementarlos sin necesidad de cumplir con las necesidades y expectativas de los ciudadanos, no sin allanar su camino al poder.

Otra pregunta que merece responderse es cuál es el efecto de un alta o baja popularidad presidencial en la elección de su sucesor. El caso de la elección presidencial del 2018 en México es ilustrativo. La elección de un candidato apartidista como candidato del PRI, cuando los niveles de popularidad del presidente Peña Nieto son históricamente bajos, permite pensar que esos niveles pueden infligir costos, no sólo para el presidente actual, sino también para su partido. El reto, entonces, sería analizar y medir tal efecto.

\section{Bibliografía}

Anderson, Cameron D. y Laura B. Stephenson (eds.), Voting Behaviour in Canada, Vancouver, UBC Press, 2010.

43 "FDR to Clinton, Mueller to? A Field Essay...". 
Beltrán, Ulises, "Aprobación presidencial: ¿honestidad o eficiencia económica?”, Nexos (en línea), junio de 2015, en http:// www.nexos.com.mx/?p=24988

Brace, Paul y Barbara Hinckley, Follow the Leader: Opinion Polls and the Modern Presidents, Nueva York, Basic Books, 1992.

— y - "Presidential Activities from Truman through Reagan: Timing and Impact", Journal of Politics, vol. 55, núm. 2, 1993, pp. 382-398.

Brody, Richard, Assesing the President: The Media, Elite Opinion, and Public Support, Stanford, CA, University Press, 1991.

Buendía, Jorge, "Economic Reform, Public Opinion, and Presidential Approval in Mexico, 1988-1993", Comparative Political Studies, vol. 29, núm. 5, 1996, pp. 566-591.

Canes-Wrone, Brandice y Kenneth W. Shotts, "The Conditional Nature of Presidential Responsiveness to Public Opinion", ponencia presentada en la Annual Meeting of the Midwest Political Science Association, Chicago, 2002.

Clarcke, Harold D. y Marianne C. Stewart, "Prospections, Retrospections, and Rationality: The «Bankers» Model of Presidential Approval Reconsidered", American Journal of Political Science, vol. 38, núm. 4, 1994, pp. 1104-1123.

Davis, Charles y Ronald E. Langley, "Presidential Popularity in a Context of Economic Crisis and Political Change: The Case of Mexico", Studies in Comparative International Development, vol. 30, núm. 3, 1995, pp. 24-48.

Edwards III, Georges C., William Mitchel y Reed Welch, "Explaining Presidential Approval: The Significance of Issue Salience”, American Journal of Political Science, vol. 39, núm. 1, 1995, pp. 108-134.

y Tami Swenson, "Who Rallies? The Anatomy of a Rally Event”, Journal of Politics, vol. 59, núm. 1, 1997, pp. 200-212.

Greene, Steven, "The Role of Character Assessments in Presidential Approval”, American Politics Research, vol. 29, núm. 2, 2001, pp. 196-210.

Gronke, Paul y Brian Newman, "FDR to Clinton, Mueller to? A «State of the Discipline» Review of Presidential Approval”, ponencia presentada en la Annual Meeting of the American Political 
Science Association, Washington, DC, agosto 31-septiembre 3, 2000, pp. 1-38.

Gronke, Paul y Brian Newman, "FDR to Clinton, Mueller to? A Field Essay on Presidential Approval", Political Research Quarterly, vol. 56, núm. 4, 2003, pp. 501-512.

-, Jeffrey Koch y J. Matthew Wilson, "Follow the Leader? Presidential Approval, Perceived Presidential Support, and Representatives' Electoral Fortunes", Journal of Politics, vol. 65, núm. 3, 2003, pp. 785-808.

Higgins, Tory E. y G. King, "Accessibility of Social Constructs: Information-Processing Consequences of Individual and Contextual Variability", en Nancy Cantor y John Kihlstrom (eds.), Personality, Cognition, and Social Interaction, Hillsdale, NJ, Erlbaum, 1981.

Iyengar, Shanto, Is Anyone Responsible? How Television Frames Political Issues, Chicago, University Press, 1991.

, Mark D. Peters y Donald R. Kinder, "Experimental Demonstrations of the «Not-So-Minimal» Consequences of Television News Programs", American Political Science Review, vol. 76, núm. 4, 1982, pp. 848-858.

y Donald R. Kinder, News that Matters, Chicago, University Press, 1987.

Kernell, Samuel, Going Public: New Strategies of Presidential Leadership, Washington, DC, Congressional Quarterly Press, $3^{\mathrm{a}}$ ed., 1997.

King, Gary y Lyn Ragsdale, The Elusive Executive, Washington, DC, Congressional Quarterly Press, 1988.

MacKuen, Michael B. y Stephen L. Coombs, More than News, Beberly Hills, Sage, 1981.

- Robert S. Erikson y James A. Stimson, "Peasants or Bankers? The American Electorate and the U.S. Economy", American Political Science Review, vol. 86, núm. 3, 1992, pp. 596-611.

Moreno, Alejandro, Confianza en las instituciones: México en perspectiva comparada, México, CESOP-Cámara de Diputados LXI Legislatura, 1997.

Mutz, Diana C., "Contextualizing Personal Experience: The Role of the Mass Media", Journal of Politics, vol. 56, núm. 3, 1994, pp. 689-714. 
Newman, Brian y Charles W. Ostrom Jr., "Explaining Seat Changes in the US House of Representatives: 1950-1998”, Legislative Studies Quarterly, vol. 27, núm. 3, 2002, pp. 383-405.

Norpoth, Helmut, "Presidents and the Prospective Voter", Journal of Politics, vol. 58, núm. 3, 1996, pp. 776-792.

Ortega, Reynaldo, Ma. Fernanda Somuano y Andrés Ruiz, "Partisan Identity and Democracy in the Mexican States", en Salvador Martí, Reynaldo Ortega, Ma. Fernanda Somuano y Claire Wright (eds.), Democracy in Mexico. Attitudes and perceptions of citizens at national and local level, Londres, Institute of Latin American Studies, 2014.

y Ma. Fernanda Somuano, Confianza y cambio político en México: contiendas electorales y el IFE, México, El Colegio de México, 2015.

Ostrom, Charles W. y Dennis M. Simon, "Promise and Performance: A Dynamic Model of Presidential Popularity", American Political Science Review, vol. 79, núm. 2, 1985, pp. 334-358.

Page, Benjamin I. y Robert Y. Shapiro, The Rational Public, Chicago, University Press, 1992.

Peffley, Mark, Ronald E. Langley y Robert Kirby Goidel, "Public Responses to the Presidential Use of Military Force: A Panel Analysis”, Political Behavior, vol. 17, núm. 3, 1995, pp. 307-337.

Ragsdale, Lyn, "The Politics of Presidential Speechmaking, 19491980", American Political Science Review, vol. 78, núm. 4, 1984, pp. 971-984.

Romero, Vidal, Impacto de la evaluación de políticas públicas en la evaluación presidencial, tesis, México, Instituto Tecnológico Autónomo de México (IтAм), 2000.

— ción presidencial", Política y gobierno, vol. temático: Desafíos de la política mexicana, 2013, pp. 139-160.

, B. Magaloni y A. Díaz-Calleros, "Presidential Approval and Public Security in Mexico's War on Crime", Latin American Politics and Society, vol. 58, núm. 2, 2016, pp. 100-123.

Scheufele, Dietram y David Tewksbury, "Framing, Agenda Setting and Priming: The Evolution of Three Media Effects Models", Journal of Communication, vol. 57, núm. 1, 2007, pp. 9-20. 
Sigelman, Lee, "Presidential Popularity and Presidential Elections", Public Opinion Quarterly, vol. 43, núm. 4, 1979, pp. 532-534.

Simon, Dennis M. y Charles W. Ostrom Jr., "The Impact of Televised Speeches and Foreign Travel on Presidential Approval", Public Opinion Quarterly, vol. 53, núm. 1, 1989, pp. 58-82.

Singer, Matthew M., "«Defendamos lo que hemos logrado». El voto económico en México durante la elección presidencial de 2006”, Política y gobierno, vol. temático: Elecciones en México, 2009, pp. 199-235.

, "Who Says «It's the Economy»? Cross-National and Cross Individual Variation in the Salience of Economic Performance", Comparative Political Studies, vol. 44, núm. 3, 2011, pp. 284-312.

_ - "Economic Voting in an Era of Non-Crisis: The Changing Electoral Agenda in Latin America 1982-2010", Comparative Politics, vol. 45, núm. 2, 2013, pp. 169-185.

Sniderman, Paul, "The New Look in Public Opinion Research”, en Ada Finifter (ed.), Political Science: The State of the Discipline II, Washington, DC, American Political Science Association, 1993, pp. 219-246.

Taylor, Shelley E. y Susan Fiske, "Salience, Attention, and Attribution: Top of the Head Phenomena", en Leonard Berkowitz (ed.), Advances in Social Psychology, Nueva York, Academic Press, 1978, pp. 249-288.

Tesser, Abraham, "Self-Generated Attitude Change", en Leonard Berkowitz (ed.), Advances in Social Psychology, Nueva York, Academic Press, 1978, pp. 289-338.

Tversky, Amos y Daniel Kahneman, "The Framing of Decisions and the Psychology of Choice”, en Robin Hogarth (ed.), Question Framing and Response Consistency, San Francisco, Jossey-Bass, 1982. Villarreal, Andrés, "Public Opinion of the Economy and the President during the Salinas Sexenio: The Role of Mass Media", documento preparado para la reunión de LASA en Washington, DC, septiembre de 1995.

Zaller, John y Stanley Feldman, "A Simple Theory of the Survey Response: Answering Questions versus Revealing Preferences”, American Journal of Political Science, vol. 36, núm. 3, 1992, pp. 579-616. 
Zizumbo-Colunga Daniel y Belinda Amador, "Corupción en México", en V. Romero, P. Parás, G. Pizzolito y E. Zechmeister (eds.), Cultura política de la democracia en México y en las Américas, 2016-2017, México, usAID-LAPOP, 2018, pp. 93-113.

\section{ApÉndice 1 \\ Cuestionario LAPOP}

¿Hasta qué punto diría usted que el gobierno actual mejora la seguridad ciudadana? ¿Ha sido usted víctima de algún acto de delincuencia en los últimos 12 meses?

¿Se siente usted muy seguro, algo seguro, algo inseguro o muy inseguro, en su barrio? ¿Hasta qué punto diría que el Gobierno actual combate el desempleo?

¿Cómo evalúa el desempeño del gobierno en el manejo de la economía?

¿Considera usted que la situación económica actual del país es mejor, igual o peor que hace doce meses?

¿Considera usted que su situación económica actual es mejor, igual o peor que la de hace doce meses?

¿Diría usted que los servicios que el municipio está dando a la gente son muy buenos, buenos, ni malos ni buenos, malos, muy malos?

¿Hasta qué punto diría que el Gobierno actual combate la corrupción en el gobierno? Identificación PAN / PRI / PRD

\section{ApÉndice 2 \\ Correlaciones de Pearson}

\begin{tabular}{|l|c|c|c|}
\hline & $\begin{array}{c}\text { Manejo de la } \\
\text { economia }\end{array}$ & $\begin{array}{c}\text { Evaluación } \\
\text { del gobierno } \\
\text { en seguridad }\end{array}$ & $\begin{array}{c}\text { Evaluación } \\
\text { del combate } \\
\text { a la corrupción }\end{array}$ \\
\hline $\begin{array}{l}\text { Intención de voto por partido en } \\
\text { el poder (2008) }\end{array}$ & $.366^{* *}$ & $.357^{* *}$ & $.350^{* *}$ \\
\hline $\begin{array}{l}\text { Intención de voto por partido en } \\
\text { el poder (2010) }\end{array}$ & $.281^{* *}$ & $.246^{* *}$ & $.248^{* *}$ \\
\hline $\begin{array}{l}\text { Intención de voto por partido en } \\
\text { el poder (2014) }\end{array}$ & $.223^{* *}$ & $.255^{* *}$ & $.279^{* *}$ \\
\hline
\end{tabular}

** Significativo al .01 (bilteral).

Fuente: Elaboración propia con datos de LAPOP 2008, 2010 y 2014. 